\title{
0 fim do fim do trabalho: uma crítica à chamada sociedade pós-industrial e sua relação com os movimentos de trabalhadores ${ }^{I}$
}

\author{
Gabriel Gomes Lourenço*
}

\begin{abstract}
Resumo: A dimensão do trabalho e os trabalhadores enquanto classe social foram objeto de preocupação nuclear em boa parte da história da sociologia, a começar pelos três autores clássicos - Karl Marx, Émile Durkheim e Max Weber -, passando por outros nomes, como Harry Braverman e Manuel Castells. Nos últimos quarenta anos, o trabalho, enquanto atividade fundamental na constituição de relações sociais (não apenas daquelas diretamente relacionadas à produção material), tem sido fortemente questionado, devido tanto a reconfigurações nas formas de trabalho quanto a alterações na formação da identidade dos trabalhadores enquanto grupo social específico. Porém, mesmo que minoritário, há um setor da academia que faz a crítica desse suposto fim da centralidade do trabalho. Este artigo sumariza o que há de central nos propositores do conceito de sociedade pós-industrial, e posteriormente, levanta argumentos contra essas teses que anunciam o fim da centralidade do trabalho. A defesa aqui é de que não há necessidade de buscar novas hipóteses a respeito do fim da centralidade do trabalho, mas sim de iniciar um movimento para entender, a partir do reconhecimento da permanência de tal centralidade, como a subjetividade da classe trabalhadora tem sido periodicamente conformada para que esta classe negue tal centralidade.
\end{abstract}

Palavras-chave: trabalho, fim da sociedade do trabalho, sujeito histórico, classes sociais.

\section{Introdução}

Uma das características mais fascinantes das ciências em geral, e das ciências sociais em particular, é o fato de se caracterizarem, em parte, como o exercício de uma capacidade puramente humana: a reflexão intelectual como mediação entre dois momentos do concreto, entre o início como um conjunto aparentemente caótico de fenômenos particulares e o fim como produto de relações determinadas, uma totalidade. 0 que será coletado do concreto para ser processado abstratamente não pode ser aleatório, trivial, e a elaboração de hipóteses tem aí um importante papel, para a qual contribui aquilo que C. Wright Mills chamou, em 1959, de imaginação

\footnotetext{
I Este artigo é uma versão ampliada do trabalho final apresentado na disciplina "Introdução à Sociologia do Trabalho", ministrada pelo professor Leonardo Gomes Mello e Silva no segundo semestre de 2011.

* Graduando em Ciências Sociais - USP.
} 
sociológica; ou seja, deve-se valorizar uma certa capacidade criativa no fazer científico.

Porém, se considerarmos que alguma diferença deve existir entre ciência e opinião, ela reside no caráter mais objetivo da primeira, quer dizer, no fato da ciência confrontar elaborações dos sujeitos com algo externo a eles mesmos. Desta forma, a sempre árdua busca de novas hipóteses para os mesmos problemas, se por um lado faz parte das ciências humanas e de seu processo de renovação contínua, por outro talvez não seja a melhor forma de explicá-los e solucioná-los; quer dizer, o confronto de proposições teóricas divergentes não só entre si, mas também delas com o próprio fato analisado, em algum momento deve levar à exclusão de pelo menos algumas dessas proposições (novamente, admitindo-se uma diferença fundamental entre ciência e opinião). Isso quando estas novas hipóteses não são meras reciclagens, hibridismos lógico-intelectuais que transformam proposições antes com coesão interna, em quebra-cabeças que não conformam um todo coerente quando vistos em sua integralidade.

Assim, o objetivo deste trabalho não é propor uma nova hipótese (uma nova interpretação, como defendem os weberianos a respeito da dinâmica do exercício sociológico) sobre uma antiga, mas atual, questão, e sim fazer a defesa de um conjunto de respostas para a mesma. No final da década de 1970, mas principalmente durante a década de 1980, foram escritos alguns textos que se tornaram referência para aqueles que defendem a entrada em cena de uma sociedade pós-industrial, caracterizada pelo fim do trabalho, ou, melhor dizendo, pelo fim da centralidade do trabalho. Autores representativos dessa corrente são Claus Offe e André Gorz.

Apesar da predominância acadêmica dessas concepções até hoje, foram elaboradas explicações e contra-argumentos àquelas afirmações. No Brasil, o intelectual que mais se dedicou a isso é provavelmente o sociólogo Ricardo Antunes, mas destacam ainda outros autores (Giovanni Alves, João Bernardo - neste caso, em Portugal - etc). A postura de retomar argumentos que criticam o suposto fim do trabalho deve-se ao entendimento de que guardam muito de seu vigor e, mais do que isso, estão em consonância com o que a realidade tem mostrado.

\section{As críticas ao trabalho enquanto fato social principal}

Aqui a opção feita foi centrar-se em Offe e Gorz, cujos textos-referência, apesar de terem quase quarenta anos, representam bem o núcleo dos argumentos que de- 
fendem o fim do trabalho, ou o fim da centralidade do trabalho. Antes, porém, será dado um panorama geral das proposições de Daniel Bell em sua obra $O$ advento da sociedade pós-industrial, a qual, publicada alguns anos antes dos textos aqui analisados, teve grandes repercussões acadêmicas e tornou-se uma referência para o grupo de autores que se dedicaram a analisar o suposto fim da sociedade do trabalho.

Segundo Bertero (2005), Bell apresenta quatro teses centrais: 1) a sociedade pós-industrial é marcada pela produção ascendente de serviços e produção descendente de bens industriais, e o poder não está mais relacionado nem à propriedade da terra nem à propriedade de capital, e sim à informação; 2) como consequência, a sociedade pós-industrial é marcada pela sindicalização crescente de "empregados de escritório" e funcionários públicos ("sindicalização das classes médias"); 3) na sociedade pós-industrial, o trabalho não tem mais a centralidade anterior e, como consequência, os conflitos a ele relacionados (quer dizer, as lutas de classes) não têm mais a mesma importância; o conflito axial agora se dá "entre os que têm o saber (os sábios) e os que não o têm (o "povão"). 0 mesmo sucede em relação ao poder, onde o saber ocupa o lugar antes ocupado pela propriedade” (BERTERo, 2005, p. 02); 4) “E a 'classe' mais importante dessa sociedade emergente é antes de tudo profissional, apoiada mais no conhecimento que na propriedade [...]. Essa nova sociedade é uma meritocracia" (BERTERo, 2005, p. 2-3).

Agora, passando aos autores de interesse maior para este trabalho, Offe conclui em seu texto Trabalho: categoria sociológica chave? da seguinte forma: "É precisamente este poder determinante abrangente do fato social trabalho (assalariado) e de suas contradições que, hoje em dia, se tornou sociologicamente questionável" (1984, p. 171). Segundo o autor, isso podia ser constatado pela mudança das preocupações e hipóteses da pesquisa social. Se antes o trabalho era visto como centro de gravidade de várias práticas sociais, certos indicadores teriam começado a pressionar por um deslocamento do trabalho enquanto preocupação teórica. Relações e identidades estabelecidas no que seria a "vida cotidiana", em contraposição ao "mundo do trabalho", teriam, se não ocupado a posição que o trabalho ocupava, ao menos ganho uma potência de determinação semelhante - quando não invertendo certas relações (OFFE, 1984, p. 172). 0 trabalho seria apenas mais um fato como tantos outros na formação da subjetividade: "Entretanto, esse fato [o aumento crescente do trabalho assalariado] tem cada vez menos importância para o conteúdo da atividade social, para a percepção de interesses, estilo de vida e assim por diante" (OFFE, 1984, p. 175). 
Nota-se que a crítica feita por Offe, neste ponto, molda-se em aspectos subjetivos, no sentido de dizerem respeito à subjetividade individual e coletiva. A defesa do enfraquecimento da determinação do trabalho na formação de identidades e interesses, ao mesmo tempo reconhecendo a expansão do trabalho assalariado, permite lançar um primeiro questionamento: não seria a questão da centralidade do trabalho uma questão essencialmente política? Quer dizer, constatada uma permanência de certas relações fundamentais da sociedade capitalista mercantil, mas sob novas formas e com alterações profundas na subjetividade individual e coletiva dos trabalhadores, o problema deveria ser então invertido. 0 que deve ser buscado não é a nova, ou as novas, fonte de identidade e interesses, mas sim os motivos pelos quais o trabalho - apesar da permanência de sua centralidade para a manutenção da forma social capitalista e, por isso, ainda fonte de severos conflitos insolúveis no longo prazo - encontra-se obscurecido como tal fonte. Propomos aqui o entendimento da questão como essencialmente política, porque questionar o trabalho na formação de identidades e interesses, em comparação com o que seria alguma fase anterior na qual o trabalho seria central, envolve o evidente enfraquecimento do movimento sindical, de partidos socialistas e comunistas em todo o mundo, após grandes conquistas trabalhistas em meados do século XX. Como o autor afirma:

De qualquer maneira, é claro que os processos multidimensionais de diferenciação, [...] tornam menos significativo o fato de ser um "empregado" e não mais um ponto de partida para associações e identidades coletivas de fundo cultural, organizacional e político (OFFE, 1984, p. 176).

É comum encontrar nessas abordagens, como ocorre com o próprio Offe, a expansão do contingente no chamado setor de serviços como algo não apenas quantitativa, mas também qualitativamente diferente. Offe argumenta que o serviço "assegura e padroniza as precondições e os limites de um tipo de trabalho ao qual ele próprio não pertence" (1984, p. 178), uma regulação feita por um trabalhador que "desafia e questiona a sociedade do trabalho e seus critérios de racionalidade (realização, produtividade, crescimento) em nome dos critérios de valor substantivos, qualitativos e 'humano'” (OFFE, 1984, p. 181).

Desenvolveremos a crítica contra esse e os argumentos anteriores em tópico posterior. No momento, apenas colocamos a ressalva de que não há indicações que sustentem a afirmação acima. Pelo contrário, os trabalhadores em serviços estão sujeitos a jornadas de trabalho legalmente estabelecidas (e também as ilegais) como 
estão os trabalhadores industriais (a título de exemplo ver abaixo a Figura 1 e a Figura 2); a remuneração salarial é fixa para uma jornada determinada, ou ainda relacionada à quantidade em várias categorias (quantidade de pacientes atendidos

\begin{tabular}{|c|c|c|c|c|c|c|c|c|c|c|c|c|}
\hline \multirow{3}{*}{$\begin{array}{l}\text { Regiōes } \\
\text { Metropolitanas }\end{array}$} & \multicolumn{10}{|c|}{$\begin{array}{c}\text { Jornada média semanal dos assalariados por setor da economia } \\
\text { Regiōes Metropolitanas e Distrito Federal 2005-2008 (em horas) }\end{array}$} & & \\
\hline & \multicolumn{4}{|c|}{ Indústria } & \multicolumn{4}{|c|}{ Comércio } & \multicolumn{4}{|c|}{ Serviços ${ }^{(1)}$} \\
\hline & 2005 & 2006 & 2007 & 2008 & 2005 & 2006 & 2007 & 2008 & 2005 & 2006 & 2007 & 2008 \\
\hline São Paulo & 43 & 43 & 43 & 43 & 47 & 46 & 46 & 46 & 42 & 42 & 42 & 42 \\
\hline Porto Alegre & 44 & 43 & 44 & 44 & 46 & 46 & 46 & 46 & 41 & 41 & 41 & 41 \\
\hline Belo Horizonte & 42 & 41 & 42 & 42 & 44 & 44 & 44 & 44 & 39 & 38 & 38 & 39 \\
\hline Salvador & 44 & 44 & 44 & 44 & 47 & 47 & 47 & 46 & 40 & 40 & 40 & 40 \\
\hline Recife & 47 & 47 & 47 & 47 & 50 & 50 & 50 & 50 & 43 & 42 & 42 & 42 \\
\hline Distrito Federal ${ }^{[2]}$ & 44 & 44 & 43 & 44 & 47 & 47 & 47 & 46 & 40 & 40 & 40 & 40 \\
\hline
\end{tabular}

Fonte: Anuário dos Trabalhadores, 10ª edição. São Paulo: DIEESE, 2009.

\section{Assalariados que trabalharam mais do que a jomada legal, por setor da economia - Regiöes Metropolitanas e Distrito Federal 2005-2008 (em \%)}

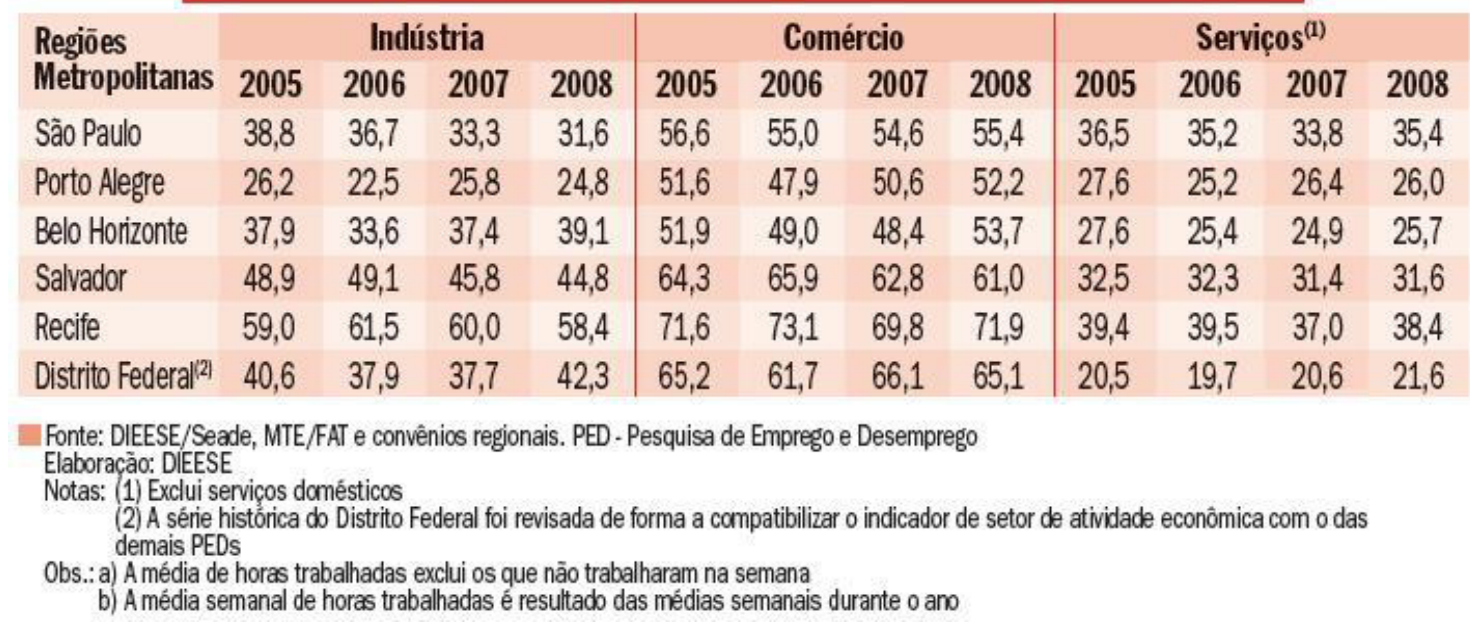

Fonte: Anuário dos Trabalhadores, 10ª edição. São Paulo: DIEESE, 2009. 
André Gorz, em seu Adeus ao proletariado (1982), tece uma crítica semelhante, quer dizer, baseada nos efeitos subjetivos da suposta sociedade pós-industrial. Ao comentar o incremento da mobilidade em detrimento da estabilidade do trabalhador em uma categoria profissional, mobilidade característica do que ele define como neoproletários, afirma que

[a] única coisa certa, para eles, é que não se sentem pertencer à classe operária nem a nenhuma outra. Não se reconhecem na categoria "trabalhador" nem naquela, sua simétrica, de "desempregado". [...] Dito de outro modo, o trabalho não pertence aos indivíduos que o executam e não é sua atividade própria: pertence ao aparelho de produção social, é repartido e programado por esse aparelho e permanece externo aos indivíduos aos quais se impõe. [...] Em lugar de engendrar um trabalhador que, transcendendo sua particularidade limitada, concebe-se a si mesmo como trabalhador social em geral, o trabalho é percebido pelos indivíduos como a forma contingente da opressão social em geral (GoRz, 1982, p. 90-91; grifo nosso).

O que chama atenção é o autor tratar como novidade um fenômeno social imanente às relações capitalistas de produção e que sempre esteve presente na socialização dos trabalhadores, qual seja, a alienação em relação ao próprio trabalho. Gorz recorre, em sua crítica, a uma identidade largamente discutida na tradição marxista, e que só é efetivada na superação da forma capitalista do trabalho (forma definida principalmente pelo assalariamento, pela propriedade privada dos meios de produção e pela forma mercadoria dos produtos do trabalho): a identidade entre indivíduo e gênero humano. Não é novidade, um fato social novo, a percepção do trabalho como opressão.

Diferentemente de outros autores que, além de defenderem o fim do trabalho, negam, parcial ou completamente, as teorias marxistas, André Gorz faz uma defesa da categoria de sujeito histórico. Porém, neste caso a não-classe de não-produtores de Gorz substituiria o proletariado, por encarnar de alguma forma o perfil desenhado por Offe para os trabalhadores em serviços:

A lógica do Capital nos conduziu ao limiar da liberação. Mas esse limiar só será transposto por uma ruptura que substitua a racionalidade produtivista por uma racionalidade diferente. [...] 0 reino da liberdade não resultará jamais dos processos materiais: só pode ser instaurado pelo ato fundador da liberdade que, reivindicando-se como subjetividade absoluta, toma a si mesma como fim supremo de cada indivíduo. Apenas a não-classe dos não-produtores é capaz desse ato fundador; pois apenas ela encarna, ao mesmo tempo, a superação do produtivismo, a recusa da ética da acumulação e a dissolução de todas as classes (GoRz, 1982, p. 93). 
Novamente, não acreditamos que haja evidências empíricas que sustentem a defesa de existir, sob o capitalismo, uma classe (ou uma "não-classe") exterior ao produtivismo e à "ética da acumulação". A título de descrição - e não de análise - das tendências contemporâneas, anexamos duas colunas do jornal Folha de São Paulo ao final deste trabalho, cujas leituras valem pelos detalhes, pelos adjetivos utilizados; pela analogia do mercado de trabalho ao processo biológico de seleção natural; pela naturalização, por parte dos entrevistados, dos processos de intensificação e extensão das jornadas de trabalho; pela visão otimista acerca da tecnologia para a adaptação dos trabalhadores a tais processos - um discurso que já começava a ser elaborado por Daniel Bell.

Seja no polo do capital, seja no polo do trabalho, não há qualquer classe que se caracterize pela escolha, pela opção, do quanto e como produzir; a dinâmica capitalista é marcada pelo fetichismo e pela reificação ${ }^{1}$ justamente por ser, ao mesmo tempo, um produto social que passa a controlar seus reprodutores.

Ainda no debate sobre sujeito histórico, Gorz, na trilha de Offe, recorre à comparação numérica entre proletariado industrial e outros contingentes de trabalhadores, como se a diminuição quantitativa dos trabalhadores industriais relativamente aos trabalhadores em serviços fosse uma demonstração do deslocamento da centralidade do proletariado enquanto sujeito. A partir da próxima seção, passamos à crítica desses argumentos do fim da sociedade do trabalho.

\section{A centralidade do trabalho e um novo momento político}

O geógrafo David Harvey, escrevendo na mesma década em que Gorz e Offe publicaram os textos aqui mencionados, defende uma tese possivelmente mais rea-

\footnotetext{
${ }^{1}$ Está fora do escopo deste artigo desenvolver uma discussão sobre os fenômenos do fetichismo e da reificação (que, em verdade, encontram-se na temática da alienação). Como qualquer categoria do universo marxiano, não existem definições sintéticas deles como conceitos, sendo necessário refazer a trajetória das principais obras e manuscritos de Marx para se chegar a uma compreensão mais total daqueles fenômenos. Todavia, a fim de aclarar o argumento que apresentamos, segue importante citação sobre o que tratamos aqui como fetichismo: "O misterioso da forma mercadoria consiste, portanto, simplesmente no fato de que ela reflete aos homens as características sociais do seu próprio trabalho como características objetivas dos próprios produtos de trabalho, como propriedades naturais sociais dessas coisas e, por isso, também reflete a relação social dos produtores com o trabalho total como uma relação social existente fora deles, entre objetos. Por meio desse quiproquó os produtos do trabalho se tornam mercadorias, coisas físicas metafísicas ou sociais. [...] Não é mais nada que determinada relação social entre os próprios homens que para eles aqui assume a forma fantasmagórica de uma relação entre coisas. [...] Isso eu chamo o fetichismo que adere aos produtos de trabalho, tão logo são produzidos como mercadorias, e que, por isso, é inseparável da produção de mercadorias." (MARX, 1996, p. 198-199). José Paulo Netto destaca um traço essencial desse fenômeno: "É de reter aqui um traço fundamental do fetichismo, que, enunciado em outras formulações, alcança nesta uma notável clareza: a supressão das mediações sociais que ele opera, subsumindo-as numa coisa substantiva e autônoma" (1981, p. 51; grifos do autor). Sobre a reificação, como fenômeno complementar ao desenvolvimento do fetichismo, ver História e Consciência de classe, de Georg Lukács.
} 
lista em relação aos outros dois autores, pois, ao levar em consideração que o modo de produção capitalista, baseado na exploração no interior das relações de trabalho, definitivamente não se encerrou, consegue captar como aqueles conflitos de classe, próprios da "sociedade industrial" - para recorrer à categorização de Daniel Bellnão se encerraram, e sim mudaram de forma. Se no alvorecer de novas sociedades é muito delicado defender uma teleologia, com a repetição ao longo de séculos de certos fenômenos, os sujeitos tornam-se capazes de entendê-los e, mais do que isso, intervir neles de acordo com certos objetivos.

$\mathrm{Na}$ realidade, não se trataria de uma marginalização do trabalho em geral, mas de uma reconfiguração do próprio capitalismo para lidar com suas crises periódicas, as quais sempre são econômicas e políticas concomitantemente. Harvey defende que a recessão de 1973 "pôs em movimento um conjunto de processos que solaparam o compromisso fordista. Em consequência, as décadas de 70 e 80 foram um conturbado período de reestruturação econômica e de reajustamento social e político" (HARVEY, 1992, p. 140). Seguir-se-ia a esse período de transição o que o autor denomina de regime de acumulação flexível, o qual se apoiaria

\begin{abstract}
na flexibilidade dos processos de trabalho, dos mercados de trabalho, dos produtos e padrões de consumo. Caracteriza-se pelo surgimento de setores de produção inteiramente novos, novas maneiras de fornecimento de serviços financeiros, novos mercados e, sobretudo, taxas altamente intensificadas de inovação comercial, tecnológica e organizacional. [...] $O$ trabalho organizado foi solapado pela reconstrução de focos de acumulação flexível em regiões que careciam de tradições industriais anteriores e pela reimportação para os centros mais antigos das normas e práticas regressivas estabelecidas nessas novas áreas (HARVEY, 1992, p.140-141; grifo nosso).
\end{abstract}

As mudanças na configuração da classe trabalhadora, a sua heterogeneização, em consonância com as transformações nas formas de organização dos processos de trabalho, foram acompanhadas de um extenso e profundo desmonte do movimento sindical. As novidades sociológicas - mas parcialmente novas - na classe trabalhadora encontradas pelos pensadores do fim da sociedade do trabalho envolvem uma diluição da principal instância de conformação das identidades e interesses.

Poderia ser argumentado que as próprias mudanças na esfera do trabalho acarretaram uma desmobilização dos trabalhadores, justamente por sua subjetividade ter transitado, enquanto produto, do trabalho para a "vida cotidiana". Ocorre que a própria crise mencionada por Harvey forçou o solapamento do sindicalismo enquanto uma solução política: 
A gradual retirada de apoio ao Estado do bem-estar social e o ataque ao salário real e ao poder sindical organizado, que começaram como necessidade econômica na crise de 1973-1975, foram simplesmente transformados pelos neoconservadores numa virtude governamental.[...]

Na medida em que o aumento da competição internacional em condições de crescimento lento forçou todos os Estados a se tornarem mais 'empreendedores' e preocupados em manter um clima favorável aos negócios, a força do trabalho organizado e de outros movimentos sociais tinha de ser contida (HARVEY, 1992, p. 158).

No fundo, o que está em discussão é a questão da relação entre ser de classe e ter consciência de classe, uma polêmica em aberto que está fora do escopo deste trabalho abordá-la em profundidade. Todavia, há que se reconhecer o papel fundamental - mas não unívoco - exercido pelos sindicatos nessa relação. Se em boa parte da história do modo de produção capitalista, o sindicato foi ao mesmo tempo propulsor e expressão da classe trabalhadora, se reconhecendo enquanto tal, no período da acumulação flexível o advento do toyotismo (ou modelo japonês) na organização da produção e dos processos de trabalho trouxe paralelamente uma reconformação do sindicalismo, agora identificado com o universo patronal valorativo e de interesses:

Parece desnecessário lembrar que essas práticas subordinam os trabalhadores ao universo empresarial, criando as condições para a implantação duradoura do sindicalismo de envolvimento, em essência um sindicalismo manipulado e cooptado. Foi a partir destes condicionantes históricos que se gestou o modelo japonês, que aqui estamos chamando de toyotismo (ANTUnEs, 2000, p. 33-34; grifos do autor).

Trata-se, assim, de uma nova forma de amoldar os trabalhadores à ordem capitalista. Mais do que a coerção de uma classe que tem consciência de ser uma classe, com interesses próprios, tem-se agora mecanismos de convencimento para que os próprios trabalhadores deslegitimem qualquer possibilidade de sentido em identificarem-se enquanto uma classe social:

A subsunção do ideário do trabalhador àquele veiculado pelo capital, a sujeição do ser que trabalha ao "espírito" Toyota, à "família" Toyota, é de muito maior intensidade, é qualitativamente distinta daquela existente na era do fordismo. Esta era movida centralmente por uma lógica mais despótica; aquela, a do toyotismo, é mais consensual, mais envolvente, mais participativa, em verdade mais manipulatória (ANTUNES, 2000, p. 42; grifos do autor).

Assim, a defesa aqui é de que essas drásticas mudanças na organização do trabalho e no perfil da classe trabalhadora - na "forma de ser" da classe, nas palavras 
de Ricardo Antunes (2000) - não se traduzem no fim da centralidade do trabalho na definição de identidades e interesses. Ele continua como centro de gravidade na conformação de subjetividades, só que ideologizadas, quer dizer, em compasso com os valores e ideias das classes dominantes. A citação mais longa a seguir traz importantes elementos para entender os desdobramentos desse processo:

\begin{abstract}
Essas transformações também afetaram as ações e práticas de greves, que tiveram sua eficácia em alguma medida reduzida em decorrência da fragmentação e heterogeneização dos trabalhadores. Ao longo da década de 1980 pôde-se constatar uma diminuição dos movimentos grevistas nos países capitalistas avançados, que por certo advém das dificuldades de aglutinar, numa mesma empresa, os operários "estáveis" e aqueles "terceirizados", que trabalham por empreitada, ou os trabalhadores imigrantes, segmentos que não contam, em grande parte, nem mesmo com a presença de representação sindical. Tudo isso dificulta ainda mais as possibilidades do desenvolvimento e consolidação de uma consciência de classe dos trabalhadores, fundada em um sentimento de pertencimento de classe [...] (ANTUNES, 2000, p. 72; grifos do autor).
\end{abstract}

Ao lado dessa radical alteração no seio do movimento sindical, há que se considerar ainda a ampliação de certos fenômenos que dificultam (quando não impossibilitam) a própria sindicalização. Não casualmente, é justamente o conjunto de trabalhadores de alta mobilidade e rotatividade reunidos por Gorz sob a denominação comum de neoproletariado o segmento da classe trabalhadora mais atingido por esse processo:

Ou seja, enquanto vários países de capitalismo avançado viram decrescer os empregos em tempo completo, paralelamente assistiram a um aumento das formas de subproletarização, através da expansão dos trabalhadores parciais, precários, temporários, subcontratados etc. (ANTUNES, 2000, p. 53).

Quanto ao predomínio numérico dos trabalhadores empregados no setor de serviços (a despeito das polêmicas do que sejam serviços), pode-se contrapor dois argumentos. 0 primeiro diz respeito ao quanto os trabalhadores de serviços se diferenciam dos trabalhadores industriais. No aspecto concreto, enquanto atividades específicas, há óbvias diferenças; todavia, isso se aplica aos diversos trabalhos executados pelos próprios operários (a atividade de um metalúrgico é muito diferente da atividade do petroleiro, por exemplo), um fato cuja percepção imediata funciona como um primeiro bloqueio para a superação de mobilizações corporativas, restritas a uma única categoria profissional. No aspecto abstrato, enquanto processos de trabalho que produzem ou não valor, aquele predomínio numérico dos trabalha- 
dores em serviços não se traduz em um deslocamento da centralidade do trabalho produtivo - quer dizer, do trabalho consumido em processos produtivos não só de valor, mas também de mais-valia -, o que coloca em questão a terceira e quarta teses de Bell (pois trabalhadores em serviços também estão inseridos em relações de valorização de capital, através de contratos de trabalho estabelecidos com proprietários de capital; Bell falha por sua orientação positivista, ao abstrair dos dados estatísticos coligidos as relações sociais correspondentes):

A atual dinâmica do capital, seja ela moderna, contemporânea, pós-moderna, globalizada, ou seja qual for o apelido com que a ideologia capitalista se [reveste], é ainda uma dinâmica do capital, ou seja, ainda existe na extração de mais-valia, de trabalho vivo. [...] Do ponto de vista do capital, não basta vender a força de trabalho, mas vendê-la para um proprietário privado dos meios de produção, que a consumirá produzindo mais-valia, ou seja, consumi-la no interior de um processo de trabalho "produtivo". Mas, se assim fosse, proletariado não seriam apenas os trabalhadores "produtivos", confundindo essa categoria com a dos operários industriais?

Aí está a raiz do erro que identificará o fenômeno da aparente diminuição do proletariado. Primeiro, que o setor produtivo não pode se restringir aos "operários industriais" [...] uma vez que, para Marx, fica evidente que o caráter produtivo de um trabalho ou serviço não se define por sua natureza, mas pela relação que estabelece com o capital, ou seja, produzindo ou não mais-valia. Assim, o mesmo trabalho ou serviço pode ou não ser produtivo (IASI, 2007, p. 116-117).

0 segundo argumento diz respeito à discussão do sujeito histórico. Convertê-la em uma questão de maioria/minoria é utilizar um parâmetro de regimes políticos democráticos e, enquanto tais, historicamente definidos. Retomando a primeira tese de Daniel Bell, segundo Bertero:

A classe operária já não é mais tão expressiva quanto o fora. Ela representa agora uma minoria cada vez mais insignificante na sociedade avançada, em franco trânsito à sociedade pós-industrial - digo isso porque, segundo Bell, ela estaria vivendo, no último quartel do século passado, a passagem de uma a outra forma (2005, p. 1).

Mas processos revolucionários - com seus sujeitos históricos - transcendem temporalmente essa regra, que é relativa a certas decisões políticas. Generalizá-la para todas as dimensões da vida social, e, além disso, para todas as épocas históricas $^{2}$, parece-nos muito com uma ideologia pretensiosamente científica, pois a regra

\footnotetext{
${ }^{2}$ Estamos assumindo aqui a alta probabilidade de que, implicitamente, e mais do que isso, inconscientemente, Bell leva em conta, na categorização "pré-industrial, industrial, pós-industrial", o critério de maiorias/minorias, e não somente na suposta passagem da sociedade industrial para a pós-industrial.
} 
democrática é tomada como pressuposto, como dada, sem qualquer autocrítica de suas determinações e limites, procedimento necessário à ciência social que, sem escapar a certa moldura ideológica, inspira também ao máximo de validade (MÉszÁros, 2008).

É por isso que, de partida, pode-se criticar a primeira tese de Daniel Bell como, ao menos, ideológica. Assim, devemos buscar a raiz do sujeito histórico em outra dimensão:

A classe universal representa os interesses gerais da sociedade, mas nada indica que ela deva ser a maioria dessa "sociedade". 0 exemplo clássico é a própria burguesia, desde sempre uma classe minoritária, mas que no quadro da crise do modo de produção feudal logrou representar, com sua ação e interesses particulares, o todo da sociedade em movimento (IASI, 2007, p. 114).

De uma forma geral, não apenas a primeira tese, mas todo o conceito formulado por Daniel Bell é ideológico. Isso não quer dizer que os fatos específicos nos quais se apoia sejam incorretos, mas sim que o uso feito deles é equivocado. Como afirmou Mandel, citando o conceito de Bell:

A crença na onipotência da tecnologia é a forma específica da ideologia burguesa no capitalismo tardio. (...) A noção de uma "sociedade pós-industrial", na qual se supõe que a estrutura social é dominada por normas de "racionalidade funcional", corresponde à mesma tendência ideológica (1985, p. 351).

0 autor defende que essa ideologia tem quatro determinações: 1) é reificada, pois coloca a tecnologia e a ciência como autônomas em relação às decisões humanas (têm um desenvolvimento de leis naturais e incessantes); 2) é incompleta e, por isso, incoerente ao falhar em explicar o retrocesso da razão; 3) promete algo que não se cumpre, pois afirma que a sociedade pós-industrial pode integrar o trabalhador em seu trabalho como uma atividade de autorrealização; 4) é uma mistificação: “O verdadeiro ídolo do capitalismo tardio é, portanto, o 'especialista' cego a todo o contexto global; o equivalente filosófico dessa especialização técnica é o neopositivismo" (MANDEL, 1985, p. 357; grifo do autor). Quanto à terceira, que nos interessa principalmente pelo significado político, contra-argumenta Mandel, citando ainda obra anterior de Daniel Bell (O fim da ideologia):

A tese da abolição, reconciliação ou repressão de todas as contradições - o fim de todas as ideologias - não passa, ela mesma, de ideologia ou falsa consciência. Sua função objetiva é simplesmente convencer as vítimas do trabalho alienado de que não faz sentido 
rebelar-se contra ele. Assim, não consegue explicar as novas explosões periódicas de rebelião, a não ser por meio de clichês psicológicos. Mas, como toda ideologia, não é apenas uma "fraude", mas um reflexo específico e socialmente determinado da realidade que mistifica (MANDEL, 1985, p. 353).

Por fim, também ele chamou a atenção para a industrialização dos serviços, quer dizer, para o fato de que as "atividades superestruturais" são incorporadas aos ciclos de produção de valor e mais-valia (lembrando que a consequência direta deste fato é que os trabalhadores em serviços, na medida que forem produtivos, são tão centrais na reprodução da sociedade capitalista quanto os trabalhadores industriais): "Muitas dessas atividades já se organizam hoje em termos industriais: são produzidas para o mercado e têm por objetivo a maximização do lucro" (MANDEL, 1985, p. 352).

\section{Considerações finais}

Essas reconfigurações socioeconômicas e políticas apontam para uma visualização diversa da questão inicial sobre a subjetividade da classe trabalhadora proposta pelos autores aqui criticados. Não é que o trabalho perdeu centralidade na formação de identidades e interesses dos próprios trabalhadores, muito menos que estejamos vivenciando o próprio fim da sociedade do trabalho, o que significaria uma tendência decrescente do contingente populacional reconhecido como força de trabalho, algo não verificado (como indica a Figura 3).

Figura 3:

\begin{tabular}{|c|c|c|c|c|c|c|c|c|c|c|c|}
\hline \multicolumn{12}{|c|}{$\begin{array}{l}\text { Força de trabalho, emprego e desemprego na OCDE } \\
\text { Paises selecionados 1993-2009 (em milhōes de pessoas) }\end{array}$} \\
\hline Força de trabalho & 1993 & 1997 & 1999 & 2001 & 2003 & 2004 & 2005 & 2006 & 2007 & 2008 & $2009^{(1)}$ \\
\hline Sete maiores páses ${ }^{14}$ & 326,6 & 337,5 & 342,7 & 349,2 & 353,3 & 355,3 & 358,4 & 361,6 & 364,3 & 366,6 & 367,6 \\
\hline Tota dos paises menores ${ }^{\text {37 }}$ & 166,1 & 180,1 & 184,2 & 188,4 & 192,9 & 196,5 & 199,1 & 202,3 & 205,2 & 208,6 & 210,1 \\
\hline TOTAL OCDE & 492,6 & 517,6 & 526,9 & 537,7 & 546,2 & 551,8 & 557,5 & 563,9 & 569,5 & 575,2 & 577,7 \\
\hline \multicolumn{12}{|c|}{ Número de empregados } \\
\hline Sete maiores páses/4 & 303,6 & 315,9 & 322,2 & 328,9 & 330,0 & 332,8 & 336,4 & 340,7 & 344,6 & 345,2 & 337,1 \\
\hline Total dos países menores ${ }^{37}$ & 152,4 & 166,9 & 171,0 & 175,4 & 178,4 & 181,6 & 184,6 & 189,1 & 193,1 & 195,9 & 191,5 \\
\hline TOTAL OCDE & 456,0 & 482,8 & 493,1 & 504,4 & 508,4 & 514,4 & 521,0 & 529,9 & 537,6 & 5411 & 528,6 \\
\hline \multicolumn{12}{|c|}{ Número de desempregados } \\
\hline Sete maiores páses ${ }^{1 / 4}$ & 23,0 & 21,6 & 20,6 & 20,3 & 23,3 & 22,5 & 22,0 & 20,9 & 19,7 & 21,4 & 30,6 \\
\hline Total dos países menores ${ }^{33}$ & 13,6 & 13,2 & 13,2 & 13,0 & 14,5 & 14,9 & 14,5 & 13,2 & 12,1 & 12,7 & 18,5 \\
\hline TOTAL OCDE & 36,6 & 34,8 & 33,8 & 33,3 & 37,8 & 37,4 & 36,5 & 34,0 & 31,9 & 34,1 & 49,1 \\
\hline
\end{tabular}

Fonte: Anuário dos Trabalhadores, 10ª edição. São Paulo: DIEESE, 2009. 
A tabela abaixo compara os crescimentos, no âmbito dos países da OCDE, do contingente empregado como força de trabalho e da população total desses países. Nota-se que o crescimento da força de trabalho é sempre maior que o crescimento populacional (a única exceção ficando entre 2008 e 2009, muito provavelmente como efeito da mais recente crise mundial). Se, por um lado, a diferença percentual é pequena, por outro devemos ter em conta de que falamos da ordem de milhões de pessoas, e, mais importante ainda, o fato de que os países de crescimento mais acelerado a partir de 2003 não compõem a OCDE, ainda que possam participar como observadores. Apenas para citar os casos mais significativos, nestes números não estão inclusos Brasil, Rússia, Índia e China (ressaltando que estes dois últimos têm uma população na casa dos bilhões de pessoas).

\begin{tabular}{|c|c|c|c|c|c|c|c|c|c|c|}
\hline & 1997 & 1999 & 2001 & 2003 & 2004 & 2005 & 2006 & 2007 & 2008 & 2009 \\
\hline Força de trabalho & 5 & 1,8 & 2 & 2 & 1 & 1 & 1,1 & 1 & 1 & 0,4 \\
\hline População & 0,72 & 0,69 & 0,72 & 0,69 & 0,69 & 0,6 & 0,66 & 0,7 & 0,68 & 0,6 \\
\hline
\end{tabular}

Fonte: OCDE. Elaboração do autor.

Adentrou-se um período do modo de produção capitalista no qual os mecanismos de coerção e convencimento, paralelamente às reestruturações produtivas marcantes do regime de acumulação flexível - o que quer dizer fragmentação e dispersão da classe trabalhadora -, disseminam-se em um grau tão profundo na vida social que as novas gerações de trabalhadores mal chegam a ter contato com expressões relativamente autônomas da classe consciente de si, como os sindicatos.

Retomando as ideias desenvolvidas na introdução, a proposição aqui é a de que não há necessidade de mais hipóteses especificamente sobre o suposto fim da centralidade do trabalho. Sem negar que existam dados empíricos propícios à aceitação dessa tese, queremos sugerir a necessidade de se aprofundar estudos para buscar como se constitui a contradição entre centralidade do trabalho como essência e não centralidade do trabalho como aparência (lembrando que este termo não é sinônimo de falsidade, mas se aproxima de "forma de expressão"). Por nada no capitalismo ser estanque, nenhum conflito ser suprimido por longo prazo, deve-se buscar entender como, a partir dessa própria centralidade, as inovações nas formas de organização do trabalho reiteram identidades e interesses divergentes daqueles da classe trabalhadora enquanto sujeito histórico. Nossa preocupação aqui é com o que seja, talvez, uma ciência social simplificadora, positivista, que não ultrapassa o 
nível dos "dados", que não se dedica a reconstruir idealmente o processo a partir do qual eles são produtos. Como exemplo, olhemos para o caso de um gerente de empresa (que é assalariado, não estamos nos referindo a proprietários/acionistas) de capital privado (portanto, produtivo):

Há uma ambiguidade na sua existência, com reflexos na consciência: como membro de classe, pertence ao proletariado; como membro de estrato, pertence aos estratos socialmente mais elevados. Conquanto isto contradiga a sua situação de classe, não a invalida. Apenas a encobre. Os estratos são categorias empíricas, fenomênicas. As classes, ao contrário, são categorias históricas e estruturais e, por isso mesmo, gerais, abstratas. Não há relação mecânica entre esses dois níveis da realidade social e sim mediações, assim como entre a existência e a consciência social (BERTERo, 2005, p. 13; grifos nossos).

Melhor dito, talvez estejamos vivenciando uma dinâmica de intensa e periódica (re)construção da subjetividade dos trabalhadores que oculta a centralidade do trabalho na sociedade capitalista.

\section{Referências}

Antunes, R. (2000). Adeus ao trabalho? Ensaio sobre as metamorfoses e a centralidade do mundo do trabalho. São Paulo, Cortez.

Bertero, J. F. (2005). Sobre a sociedade pós-industrial. Comunicação apresentada no IV Colóquio Marx e Engels em Campinas-SP. Disponível em <http://www.unicamp. br/cemarx/ANAIS\%20IV\%20COLOQUIO/comunica\%E7\%F5es/GT3/gt3m2c4.pdf>. Acesso em: 14 jun. 2012.

Gorz, A. (1982). Adeus ao proletariado. Rio de Janeiro, Forense Universitária.

Harvey, D. (1992). A condição pós-moderna. São Paulo, Loyola.

IASI, M. (2007). Ensaios sobre consciência e emancipação. São Paulo, Expressão Popular.

MAndel, E. (1985) O capitalismo tardio. São Paulo, Nova Cultural.

MarX, K. (1996). O Capital: crítica da economia política. Vol. I, tomo I. São Paulo, Nova Cultural.

MÉszÁRos, I. (2008). Filosofia, ideologia e ciência social. São Paulo, Boitempo.

NeTto, J. P. (1981). Capitalismo e reificação. São Paulo, Livraria Editora Ciências Humanas.

OFfE, C. (1984). Capitalismo desorganizado. São Paulo, Brasiliense.

Recebido em abril/2012

Aprovado em julho/2012 


\section{ANEXO 1 \\ E-mail e celular estendem jornada de trabalho para casa e até as férias}

Tecnologia eleva número de horas trabalhadas; brasileiro também passa mais tempo no escritório. Expansão da economia e promoções ajudam a explicar aumento da carga horária, aponta pesquisa.

\section{Érica Fraga, de São Paulo}

"Eu olho e-mail em casa, andando na rua, no restaurante. Parece que o trabalho não me deixa". A declaração da publicitária Júlia Eboli, coordenadora de marketing da Tecla Internet, mostra a realidade de um contingente cada vez maior de profissionais. A combinação entre crescimento mais intenso da economia e avanço nas tecnologias de comunicação tem resultado em aumento das horas trabalhadas no Brasil.

Sete em cada dez profissionais - que ocupam cargos como analista, gerente e supervisor - afirmam que passam mais tempo no escritório hoje do que há cinco anos.

Mais da metade diz que o teto da carga horária no escritório saltou de oito para dez horas diárias, e quase $80 \%$ são acionados nos momentos de lazer e descanso via mensagens no celular.

Nem as férias escapam: mais de $50 \%$ dos funcionários de empresas que atuam no país respondem a e-mails de trabalho nesse período.

Esses são resultados de pesquisa feita pela Asap, consultoria de recrutamento de executivos, a pedido da Folha. Foram ouvidas 1.090 pessoas com renda mensal entre $\mathrm{R} \$ 5.000$ e $\mathrm{R} \$ 15$ mil.

A expansão da economia e as promoções no trabalho são as razões para o aumento da carga horária de trabalho, indica a maior parte dos entrevistados.

"Nossa empresa é vítima positiva da expansão do crédito. Estamos trabalhando mais", diz Daniel Polistchuck, diretor de tecnologia da Crivo, que desenvolve programas para análise de crédito.

Para Carlos Eduardo Ribeiro Dias, sócio e presidente-executivo da Asap, há um descompasso entre o ritmo do mercado de trabalho e o de formação acadêmica e profissional. "As pessoas estão sendo promovidas mais cedo, mas nem sempre estão preparadas. 0 resultado: trabalham mais."

\section{Tecnologia}

O avanço da tecnologia tem aproximado mais o profissional do trabalho. "Hoje, há aplicativos de comunicação instantânea que te acompanham o dia todo no celu- 
lar. Tento me policiar, mas passei a trabalhar mais", diz o espanhol Jose Luis Gallardo, gerente de canais da Kingston no Brasil.

Rodrigo Vianna, diretor da HAYS, empresa de recrutamento de executivos, diz que, sem as novas tecnologias, "as pessoas viveriam praticamente dentro das empresas".

"Com a globalização, não há mais fuso horário. É preciso ficar ligado o tempo todo. A tecnologia, nesse sentido, veio para ajudar."

Mas o excesso de trabalho tem consequências. Para Elaine Saad, gerente-geral da Right Management, o brasileiro tem forte apego à tecnologia e exacerba o uso de mensagens pelo celular. "Isso faz que as pessoas trabalhem no horário do descanso. E, se você não responde a um e-mail e seu colega responde, você fica com medo de perder o emprego."

Fonte: Jornal Folha de São Paulo, Caderno Mercado, 28/11/2011.

\section{ANEXO 2 \\ Ficou mais difícil determinar a hora do lazer e a hora do trabalho Regina Madalozzo, Especial para a Folha}

No livro "Alice Através do Espelho", de Lewis Carroll, a personagem Alice é confrontada pela Rainha de Copas: "É preciso correr o máximo possível para ficar parado no mesmo lugar".

0 que parece impossível é realidade: no trabalho competitivo, cada pessoa precisa se dedicar ao máximo para manter seu emprego e sua empregabilidade. Foi por meio de computadores portáteis e de telefones com aplicativos que passamos a trabalhar mesmo em horário de folga. Num passado remoto, era plenamente possível separar o tempo gasto no trabalho e o tempo dedicado à vida pessoal.

Hoje, em segundos, é possível enviar e atender demandas. Fica bem mais complicado determinar a hora do trabalho e a hora do lazer. Mas a tecnologia, com implicações terríveis para nosso bem-estar - como doenças relacionadas ao estresse, perda da felicidade, decepção com o trabalho -, permitiu a jornada flexível e o trabalho à distância.

De fato, uma conquista, em algumas empresas, foi permitir que o próprio funcionário escolha quando e de onde trabalhar. 0 que importa não é o tempo dentro da empresa, mas o que é entregue a ela. 
Como a biologia, que estuda a seleção natural das espécies, o mercado de trabalho encontra formas de selecionar os melhores indivíduos. Cabe a cada um estabelecer os limites que julgar necessários, ciente das consequências - seja para a saúde ou para a carreira.

Algumas empresas celebram a corrida da seleção natural, outras buscam coordenar os objetivos de eficiência e lucratividade com indivíduos satisfeitos com o trabalho e a vida pessoal. 0 que você escolhe?

Regina Madalozzo é Ph.D. pela Universidade de Illinois e professora do Insper.

Fonte: Jornal Folha de São Paulo, Caderno Mercado, 28/11/2011. 